\title{
Sensory acceptability and fatty acid profile of fish crackers made from Carassius gibelio
}

\author{
Levent İZC $\dot{I}^{1 *}$, Şengül BİLGİN ${ }^{1}$
}

\begin{abstract}
In this study, our aim was to consider the production of fish crackers using Carassius gibelio and to investigate the fatty acid profile and sensory quality of the fish crackers. Fish cracker mixture with a ratio 3.5:1.5 (minced fish/wheat starch) was obtained. Based on the total minced fish and starch level, $1.75 \%$ salt, $0.25 \%$ black pepper, $2 \%$ sunflower oil, $1 \%$ baking powder and $10 \%$ cold water $\left(4^{\circ} \mathrm{C}\right)$ were added and stirred until a homogenous mixture was obtained. The mixture was compressed in an extractor and baked. The moisture content of minced fish (CMF), cracker dough (CD) and crackers (CCr) was 77.73 $\pm 0.14 \%, 63.10 \pm$ $2.18 \%$ and $7.95 \pm 0.67 \%$ respectively. The $\mathrm{n} 6 / \mathrm{n} 3$ ratio of crackers was $2.61 \pm 0.20$, PUFA/SFA ratio $2.28 \pm 0.06$ and DHA/EPA ratio $1.81 \pm 0.01$. The overall acceptability score obtained by the sensory evaluation of panelists was very high $(8.09 \pm 0.25)$.
\end{abstract}

Keywords: fish cracker; Carassius gibelio; baking; fatty acid; sensory quality.

Practical Application: Production of cracker from fish flesh.

\section{Introduction}

Worldwide demand for ready-to-eat products is constantly increasing. With today's fast pace of life, ready-to-eat food has become a popular product. Consequently, production of this kind of food has become widespread in the food industry. Formulating a healthy and balanced diet has become an important problem for societies. Fish is a food that has an important place in human nutrition.

Cracker type food in Turkey, consumed by every age group from 7 to 70, is one of the most widely marketed and consumed ready-to-eat products. Different varieties of these products are available to consumers in all markets. Supplementing this type of product with fish is an important matter that should be considered in terms of a healthy and balanced diet.

Fish and shellfish provide an almost unlimited variety of fatty acids with beneficial roles for human health. The overall net effect of the consumption of fish and fish oils appears to reduce the risk of coronary heart diseases. The potential health benefits related to fish consumption are due to the presence of proteins, unsaturated essential fatty acids, minerals, and vitamins. Additional health benefits deriving from the consumption of fish or fish lipids may be related to PUFAs, especially n3 PUFAs (Guler et al., 2008).

The continuous development of processed food formulations plays a role in the advance of the welfare of a country. This development also contributes many benefits to the life of the average consumer (Kasapis, 2009).

Using the meat of C. gibelio, which is a dominant species in natural and dam lakes, for low value cracker production not only increases the value of the species and contributes to the national economy but also provides a new product for the food industry. In addition, preferable healthy products can be obtained. The fact that such products are particularly popular with children adds importance to this kind of product.
Cracker-related studies in the literature indicate that, basically, fish crackers are produced by mixing fish flesh with starch and water (Nurul et al., 2009). Fish cracker is a popular snack food and a rapidly growing export industry in Malaysia ('keropok'), Indonesia (known as kerupuk) and other Southeast Asian countries (Cheow \& Yu, 1997).

Cheow \& Yu (1997) studied the effect of fish protein, sugar, salt and monosodium glutamate (MSG) on starch gelatinisation of fish starch mixture. Cheow et al. (1999a) examined the effects of salt, sugar and MSG on viscoelastic properties of fish cracker gel. Cheow et al. (1999b) studied the effect of salt and sugar on expansion and microstructure of fish crackers. Kyaw et al. (1999) investigated the effect of steaming time on linear expansion of fish crackers. Kyaw et al. (2001a) studied the effect of fish starch content on microelastic properties and microstructure of fish cracker. Kyaw et al. (2001b) looked at the effect of cooking pressure on expansion and microstructure of fish crackers. Cheow et al. (2004) determined the relationship between the physicochemical properties of starch and the expansion in fish crackers, Teixeira et al. (2000) studied the thin layer drying process on thin disk geometry of crackers obtained from the dough produced from Tilapia nilotica fillets, tapioca starch and the other ingredients theoretically and experimentally. Neiva et al. (2011) produced fish cracker as a traditional product with an innovative approach using fish species of low value such as Menticirrhus americanus and Umbrina coroides. Nguyen et al. (2013) produced crackers from shrimp and Wang et al. (2012) produced it from Ctenopharyngodon idella and examined some of its features.

The aim of this study was to evaluate low value C. gibelio in a different way, to increase fish consumption and also to determine the fatty acid profile and the sensory acceptance of the cracker. 


\section{Materials and methods}

\subsection{Preparation of the fish sample}

C. gibelio samples were purchased from the local fish market (Eğirdir-Turkey). Fish with the average weight $307.07 \pm 19.05 \mathrm{~g}$ and length $25.39 \pm 0.47 \mathrm{~cm}$ were used. Fish were transferred to the laboratory in styrofoam boxes with ice. First, the fish were decapitated, gutted and skinless fillets were produced. The resulting fillets were stored at $-18{ }^{\circ} \mathrm{C}$ for one month until the crackers were made.

\subsection{Preparation of cracker samples}

First, the fillets that had been stored at $-18^{\circ} \mathrm{C}$ were minced and a sufficient quantity of sample was taken for analysis. Fish crackers were produced by modification of the method reported by Civdir (2011). Mixture with a ratio 3.5:1.5 (minced fish/wheat starch) was made. Based on the total minced fish and starch, $1.75 \%$ salt, $0.25 \%$ black pepper, $2 \%$ sunflower oil, $1 \%$ baking powder and $10 \%$ cold water $\left(4^{\circ} \mathrm{C}\right)$ were included and stirred until a homogenous mixture was obtained. A sufficient quantity of sample was separated from the resulting dough for analysis. The mixture was compressed as long rods with a $0.7 \mathrm{~mm}$ diameter extractor on a tray covered with oven paper. The tray was placed in an oven previously heated to $150 \pm 1{ }^{\circ} \mathrm{C}$ and baked for 75 minutes. The fish crackers were cooled to room temperature and packed in closed bags.

\subsection{Moisture analysis}

Moisture analysis of all samples was performed using automatic moisture analyzer (AND MX- 50, Japan).

\subsection{Fatty acid methyl ester (FAME) analysis}

Lipid extraction was performed according to the method reported by Bligh \& Dyer (1959). Methyl esters were obtained by a small modification of the method reported by Ichihara et al. (1996). Lipid samples were diluted with $2 \mathrm{ml}$ of $\mathrm{n}$-heptane in a clean stoppered tube and then, $4 \mathrm{~mL}$ of potassium hydroxide ( $2 \mathrm{M} \mathrm{KOH}$ in methanol) was added. The mixture was vortexed for two minutes at room temperature and centrifuged at $4000 \mathrm{rpm}$ for ten minutes. Finally, the top layer was separated for FAME analysis.

\subsection{Gas chromatographic condition}

Fatty acid analysis was performed using a Clarous GC 500 apparatus (Perkin- Elmer, USA), flame ionization detector and a silica capillary column ( $30 \mathrm{mx}, 0.32 \mathrm{~mm}$ ID, $0.25 \mu \mathrm{m}$ BP20 $0.25 \mathrm{UM}$; USA). Injector and detector temperatures were maintained at $220^{\circ} \mathrm{C}$ and $280^{\circ} \mathrm{C}$ respectively. The furnace temperature was also maintained at $140{ }^{\circ} \mathrm{C}$ for five minutes. Later the temperature was increased first to $200{ }^{\circ} \mathrm{C}$ by increasing $4{ }^{\circ} \mathrm{C}$ per minute and then to $220^{\circ} \mathrm{C}$ by increasing $1{ }^{\circ} \mathrm{C}$ per minute. A split ratio 1:50 was used. Fatty acid was identified by comparing the standard FAME mixture consisting of 37 items, depending on the time to come. The results of GC analysis were expressed as $\% \pm$ standard error.

\subsection{Sensory analysis}

Sensory evaluation of cracker samples was performed using the method reported by Kyaw et al. (2001b) with a small modification based on flavor, appearance, odor, color, crispiness and the overall acceptability parameters on 9-point hedonic scale (1-extremely dislike and 9-extremely like).

\subsection{Statistical analysis}

The data obtained in this study were analyzed using the SPSS 9.0 statistical software package by analysis of variance (one-way ANOVA), and averages derived from significant variance sources were compared with Duncan Multiple Range Test set to $\mathrm{P}<0.05$ significance level.

\section{Results}

According to the results of moisture analysis, minced fish (CMF), cracker dough (CD) and crackers (CCr) were determined $77.73 \pm$ $0.14 \%, 63.10 \pm 2.18 \%$ and $7.95 \pm 0.67 \%$ respectively. Changes in moisture contents were found significant for all groups $(\mathrm{P}<0.05)$.

In this study $\mathrm{C}_{16: 0,}$ that is the maximum ratio of saturated fatty acids (SFA) in C. gibelio meat decreased substantially during cracker production steps, cracker dough and cracker samples $(\mathrm{P}<0.05)$. On the other hand, $\mathrm{C}_{18 \cdot 1 \mathrm{n}-9}$ the maximum ratio of monounsaturated fatty acids $(\mathrm{MUFA})(\mathrm{P}<0.05)$ and $\mathrm{C}_{18: 2 \mathrm{n}-6}$ the maximum ratio of polyunsaturated fatty acids $(\mathrm{P}<0.05)$ increased respectively. In the cracker samples, $\mathrm{n} 6 / \mathrm{n} 3$ ratio was $2.61 \pm 0.20$, PUFA/SFA ratio was $2.28 \pm 0.06$ and DHA/EPA ratio was 1.81 \pm 0.01 (Table 1).

Table 1. Fatty acid profile of crackers produced from C. gibelio (\%)*.

\begin{tabular}{|c|c|c|c|}
\hline & $\mathrm{CMF}$ & $\mathrm{CD}$ & $\mathrm{CCr}$ \\
\hline $\mathrm{C}_{12: 0}$ & $0.04 \pm 0^{\mathrm{ab}}$ & $0.02 \pm 0^{\mathrm{b}}$ & $0.06 \pm 0.01^{\mathrm{a}}$ \\
\hline $\mathrm{C}_{14: 0}$ & $2.01 \pm 0.24^{\mathrm{a}}$ & $0.96 \pm 0.01^{\mathrm{b}}$ & $0.56 \pm 0.06^{\mathrm{b}}$ \\
\hline $\mathrm{C}_{14: 1}$ & $0.22 \pm 0.01^{\mathrm{a}}$ & $0.11 \pm 0^{\mathrm{b}}$ & $0.08 \pm 0.01^{b}$ \\
\hline $\mathrm{C}_{15: 0}$ & $0.13 \pm 0^{\mathrm{a}}$ & $0.08 \pm 0.01^{\mathrm{a}}$ & $0.12 \pm 0.03^{a}$ \\
\hline $\mathrm{C}_{15: 1}$ & $0.17 \pm 0.01^{\mathrm{a}}$ & $0.10 \pm 0^{\mathrm{b}}$ & $0.10 \pm 0.01^{\mathrm{b}}$ \\
\hline $\mathrm{C}_{16: 0}$ & $14.41 \pm 0.23^{\mathrm{a}}$ & $10.23 \pm 0.08^{b}$ & $10.64 \pm 0.83^{b}$ \\
\hline $\mathrm{C}_{16: 1}$ & $6.69 \pm 0.07^{a}$ & $3.62 \pm 0.07^{b}$ & $3.36 \pm 0.33^{\mathrm{b}}$ \\
\hline $\mathrm{C}_{17: 0}$ & $0.25 \pm 0^{\mathrm{a}}$ & $0.12 \pm 0.02^{\mathrm{b}}$ & $0.12 \pm 0.01^{\mathrm{b}}$ \\
\hline $\mathrm{C}_{17: 1}$ & $0.36 \pm 0.02^{\mathrm{a}}$ & $0.14 \pm 0.01^{b}$ & $0.19 \pm 0.01^{b}$ \\
\hline $\mathrm{C}_{18: 0}$ & $3.53 \pm 0.05^{\mathrm{a}}$ & $3.40 \pm 0.01^{\mathrm{a}}$ & $4.21 \pm 0.47^{\mathrm{a}}$ \\
\hline$C_{18: 1 n-9}$ & $16.05 \pm 0.07^{c}$ & $32.77 \pm 0.30^{\mathrm{a}}$ & $27.95 \pm 0.92^{b}$ \\
\hline $\mathrm{C}_{18: 1 \mathrm{n}-7}$ & $4.04 \pm 0.12$ & - & - \\
\hline $\mathrm{C}_{18: 2 \mathrm{n}-6}$ & $12.24 \pm 0.59^{c}$ & $28.99 \pm 0.26^{\mathrm{a}}$ & $25.42 \pm 0.52^{b}$ \\
\hline $\mathrm{C}_{18: 3 \mathrm{n}-3}$ & $2.29 \pm 0.12^{\mathrm{a}}$ & $1.36 \pm 0.05^{\mathrm{b}}$ & $1.49 \pm 0.20^{\mathrm{b}}$ \\
\hline $\mathrm{C}_{20: 0}$ & $0.12 \pm 0.01^{\mathrm{a}}$ & $0.13 \pm 0.02^{\mathrm{a}}$ & $0.14 \pm 0.07^{\mathrm{a}}$ \\
\hline $\mathrm{C}_{20: 1}$ & $1.14 \pm 0.04^{\mathrm{a}}$ & $1.41 \pm 0.25^{\mathrm{a}}$ & $1.71 \pm 0.03^{\mathrm{a}}$ \\
\hline $\mathrm{C}_{20: 2}$ & $6.67 \pm 0.36^{\mathrm{a}}$ & $3.18 \pm 0^{\mathrm{b}}$ & $4.25 \pm 0.47^{\mathrm{b}}$ \\
\hline $\mathrm{C}_{20: 3 \mathrm{n}-6}$ & $0.35 \pm 0.09^{a}$ & $0.13 \pm 0^{\mathrm{a}}$ & $0.36 \pm 0.08^{\mathrm{a}}$ \\
\hline $\mathrm{C}_{20: 4 \mathrm{n}-6}$ & $0.51 \pm 0.03^{\mathrm{a}}$ & $0.25 \pm 0^{\mathrm{b}}$ & $0.30 \pm 0.01^{b}$ \\
\hline $\mathrm{C}_{20: 5 \mathrm{n}-3}$ & $4.25 \pm 0.03^{\mathrm{a}}$ & $2.12 \pm 0.01^{\mathrm{c}}$ & $3.04 \pm 0.30^{\mathrm{b}}$ \\
\hline$C_{22: 1 n-9}$ & $0.07 \pm 0.01^{\mathrm{ab}}$ & $0.04 \pm 0.02^{b}$ & $0.10 \pm 0.01^{\mathrm{a}}$ \\
\hline $\mathrm{C}_{22: 2}$ & $0.89 \pm 0.02^{\mathrm{a}}$ & $0.42 \pm 0.01^{\mathrm{b}}$ & $0.61 \pm 0.11^{\mathrm{b}}$ \\
\hline $\mathrm{C}_{23: 0}$ & $0.89 \pm 0.04^{\mathrm{a}}$ & $0.21 \pm 0.20^{\mathrm{b}}$ & $0.82 \pm 0.05^{\mathrm{a}}$ \\
\hline $\mathrm{C}_{24: 0}$ & $1.90 \pm 0.09^{a}$ & $0.79 \pm 0.04^{b}$ & $1.34 \pm 0.40^{\mathrm{ab}}$ \\
\hline $\mathrm{C}_{22: 6 \mathrm{n}-3}$ & $6.45 \pm 0.07^{a}$ & $2.50 \pm 0.03^{c}$ & $5.50 \pm 0.49^{b}$ \\
\hline n6/n3 & $1.01 \pm 0.04^{c}$ & $4.93 \pm 0.07^{\mathrm{a}}$ & $2.61 \pm 0.20^{\mathrm{b}}$ \\
\hline PUFA/SFA & $1.45 \pm 0.07^{\mathrm{b}}$ & $2.45 \pm 0.06^{\mathrm{a}}$ & $2.28 \pm 0.06^{\mathrm{a}}$ \\
\hline DHA/EPA & $1.52 \pm 0.03^{\mathrm{b}}$ & $1.18 \pm 0.01^{c}$ & $1.81 \pm 0.01^{\mathrm{a}}$ \\
\hline
\end{tabular}


Panelists evaluated flavor, appearance, odor, color, crispiness and overall acceptability parameters. Sensory analysis results; flavor, appearance, odor, color, crispiness and overall acceptability were determined $8.18 \pm 0.26,7.64 \pm 0.24,7.82 \pm 0.23,7.64 \pm$ $0.20,8.18 \pm 0.30$ and $8.09 \pm 0.25$ respectively. According to the results of sensory analysis, it was concluded that panelists liked C. gibelio crackers.

\section{Discussion}

In this study fish crackers were obtained from C. gibelio, a common low value fish species in natural and dam lakes in our country and fatty acid content and sensory characteristics were evaluated.

İzci (2010) identified the moisture level in C. gibelio fresh samples as $76.243 \pm 0.392 \%$. Nurul et al. (2009) determined a moisture rate of $8.50 \pm 0.44 \%$ in the cracker group with the highest fish mixture level (fish: flour 2.5:1). Kyaw et al (2001a) proved that moisture content increased with increasing fish ratio in cracker dough mixture (fish: starch) with a moisture content of $57.23 \pm$ $3.58 \%$ if the mixture ratio of the dough was 50:50. Okraku-Offei (1974) produced crackers using different fish species and showed that drying crackers changed the moisture content by $8-10 \%$. Neiva et al. (2011) produced fish crackers using minced fish of two different fish species by way of frying and microwave cooking methods and found the moisture content was $0.48 \pm 0.06 \%$ and $3.12 \pm 0.15 \%$ respectively. Duman et al. (2012) obtained chips using surimi powder produced from Aspius vorax. The amount of moisture in chips with different proportions of surimi powder was found to vary between $6.64 \pm 0.28 \%$ and $7.81 \pm 0.23 \%$. In a study of $O$. mykiss crackers with different mince levels, Civdır (2011) found that while the moisture level in the minced fish group was $74.106 \pm 0.491 \%$, it was $56.120 \pm 0.500 \%$ in the cracker dough and $6.970 \pm 0.305 \%$ in crackers in the $2: 3$ (fish: starch) group, $56.046 \pm 1.873 \%$ in cracker dough and $6.423 \pm 0.530 \%$ in crackers in the $1: 1$ group, $58.776 \pm 0.808 \%$ in cracker dough and $5.556 \pm 0.132 \%$ in crackers in the $3: 2$ group. Our study is almost parallel to the aforementioned study findings.

Özoğul et al. (2007) found the Cyprinus carpio DHA/EPA ratio was 1.40 and $n 6 / n 3$ ratio as 0.91 respectively. İzci (2010) determined quality features of fish finger produced from $C$. gibelio and established that $\mathrm{C}_{16: 0}$ was the most abundant fatty acid in SFA, $\mathrm{C}_{18: 1 \mathrm{n}-9}$ in MUFA and $\mathrm{C}_{18: 2 \mathrm{n}-6}$ in PUFA in the raw material. According to Civdir (2011), in crackers produced using rainbow trout $(O$. mykiss) fillets with different minced fish: starch ratio (3:2) using a similar method, $\mathrm{C}_{16: 0}$ was the most abundant among saturated fatty acids. Average $C_{16: 0}$ levels in control samples (minced fish), in cracker dough and following heat treatment were $15.235 \pm 1.105 \%, 11.960 \pm 0.150 \%$ and $11.615 \pm 0.075 \%$ respectively. There was a negligible change between crackers and cracker dough samples $(\mathrm{P}>0.05)$. Similarly, $\mathrm{C}_{18: 1 \mathrm{n}-9}$ was most abundant among monounsaturated fatty acids. Average $\mathrm{C}_{18: 1 \mathrm{n}-9}$ levels in control samples in cracker dough and following heat treatment were $21.245 \pm 3.445 \%, 32.015 \pm 0.075 \%$ and 32.980 $\pm 0.300 \%$ respectively. Again, there was insignificant change between crackers and cracker dough $(\mathrm{P}>0.05)$. $\mathrm{C}_{18: 2 \mathrm{n}-6}$ was most abundant among polyunsaturated fatty acids. Average $C_{18: 2 \mathrm{n}-6}$ levels in control samples, in cracker dough and following heat treatment were $16.775 \pm 0.735 \%, 20.745 \pm 0.685 \%$ and $22.055 \pm$ $0.315 \%$ respectively. Among the most important polyunsaturated fatty acids, levels of $\mathrm{C}_{22: 6 \mathrm{n}-3}$ and $\mathrm{C}_{20: 5 \mathrm{n}-3}$ in crackers were 7.825 $\pm 0.325 \%$ and $2.505 \pm 0.115 \%$ respectively. Neiva et al. (2011) produced minced fish using equal proportions of two low value fish species. The resulting mince with equal ratios of starch (minced fish: starch, 50:50) and different ingredients was used to make fish crackers by an innovative approach with two different cooking methods. Following a preliminary process, fatty acids DHA and EPA were not identified in fried crackers but found to be $21.0 \%$ and $6.54 \%$ in those baked in the microwave oven respectively. The level of total $n 6$ fatty acids was higher in fried crackers than those crackers cooked in the microwave, but total n 3 fatty acid density was higher in those cooked in the microwave.

Kyaw et al. (2001b) used different methods and different kinds of starch (tapioca and wheat starch) to produce the fish crackers. In their study, following the application of different temperature and pressure, they realized a significant $(\mathrm{P}<0.05)$ reduction in crispiness and overall acceptability of crackers produced by including tapioca starch to the mixture with increasing temperature, but the flavor did not significantly change. However, including wheat starch to the cracker did not significantly $(\mathrm{P}>0.05)$ change the flavor but caused a significant $(\mathrm{P}<0.05)$ increase in crispiness and overall acceptability. Okraku-Offei (1974) found that the most popular group in terms of both flavor and crispiness was the cracker group with a fish: starch ratio 1:1. Civdir (2011) produced crackers from O. mykiss with different proportions of fish and starch content using a similar method. The researcher reported that panelists generally preferred crackers with a ratio 1:1 (minced fish: wheat starch) but when panelists evaluated flavor, appearance, odor, color, crispiness and overall acceptability in the cracker with a ratio 3:2 there as no significant statistical difference between these parameters $(\mathrm{P}>0.05)$. King (2002) produced crackers from the Brachydeuterus auritus species using different levels of minced fish and cassava starch. The most acceptable type of cracker was a cracker with a ratio of 1:1 and 2:3 (fish: starch) dried and fried in deep vegetable oil. Duman et al. (2012) produced chips using surimi powder at different rates and found that overall acceptability in the surimi powder group was lower than the unused control group. Wang et al. (2012) reported that adding green banana flour provided a reduction in the color, texture and crispiness of fish crackers in a study with C. idealla species.

\section{Conclusion}

Crackers produced from C. gibelio were found to be a valuable source of food in terms of important polyunsaturated fatty acids such as DHA and EPA and were highly accepted by the panelists. We believe that inducing consumption of crackers enriched with fish flesh is critical both in terms of a healthy and balanced diet and promote of fish consumption.

\section{References}

Bligh, E. G., \& Dyer, W. J. (1959). A rapid method of total lipid extraction and purification. Canadian Journal of Biochemistry and Physiology, 37(8), 911-917. http://dx.doi.org/10.1139/o59-099. PMid:13671378.

Cheow, C. S., \& Yu, S. Y. (1997). Effect of fish protein, salt, sugar, and monosodium glutamate on the gelatinization of starch in fish-starch mixtures. Journal of Food Processing and Preservation, 21(2), 161-177. http://dx.doi.org/10.1111/j.1745-4549.1997.tb00774.x.

Cheow, C. S., Yu, S. Y., \& Howell, N. K. (1999a). Effect of salt, sugar and monosodium glutamate on the viscoelastic properties of fish 
cracker ('keropok') gel. Journal of Food Processing and Preservation, 23(1), 21-37. http://dx.doi.org/10.1111/j.1745-4549.1999.tb00367.x.

Cheow, C .S., Yu, S. Y., Howell, N. K., Man, C., \& Muhammad, K. (1999b). Effect of fish, starch and salt contents on the microstructure and expansion of fish crackers ('keropok'). Journal of the Science of Food and Agriculture, 79(6), 879-885. http://dx.doi.org/10.1002/ (SICI)1097-0010(19990501)79:6<879::AID-JSFA295>3.0.CO;2-P.

Cheow, C. S., Kyaw, Z. Y., Howell, N. K., \& Dzulkifly, M. H. (2004). Relationship between physicochemical properties of starches and expansion of fish cracker 'keropok'. Journal of Food Quality, 27(1), 1-12. http://dx.doi.org/10.1111/j.1745-4557.2004.tb00633.x.

Civdır, A. (2011). Production of cracker from rainbow trout (Oncorhynchus mykiss W.,1792) and determination of some quality properties (Master's thesis). Süleyman Demirel University, Isparta.

Duman, M., Özpolat, E., \& Gül M. R. (2012). The chips produced using surimi powder different rates of chemical composition and sensory quality determination. Journal of FisheriesSciences.com, 6(4), 282-286.

Guler, G. O., Kiztanir, B., Aktumsek, A., Citil, O. B., \& Ozparlak, H. (2008). Determinetion of the seasonal changes on total fatty acid composition and $\omega 3 / \omega 6$ ratios of carp (Cyprinus carpio L.) muscle lipids in Beyşehir Lake (Turkey). Food Chemistry, 108(2), 689-694. http://dx.doi.org/10.1016/j.foodchem.2007.10.080. PMid:26059149.

Ichihara, K., Shibahara, A., Yamamoto, K., \& Nakayama, T. (1996). An improved method for rapid analysis of the fatty acids of glycerolipids. Lipids, 31(5), 535-539. http://dx.doi.org/10.1007/BF02522648. PMid:8727647.

İzci, L. (2010). Utilization and quality of fish fingers from prussian carp (Carassius gibelio Bloch, 1782). Pakistan Veterinary Journal, 30(4), 207-210. Retrieved from http://www.pvj.com.pk/archive/ Volume_30_Issue_4_2010.htm

Kasapis, S. (2009). Developing minced fish products of improved eating quality:an interplay of instrumental and sensory texture. International Journal of Food Properties, 12(1), 11-26. http://dx.doi. org/10.1080/10942910802252171.

King, M. A. (2002). Development and sensory acceptability of crackers made from the big-eye fish (Brachydeuterus auritus). Food and Nutrition Bulletin, 23(3), 317-320. PMid:12362597.

Kyaw, Z. Y., Yu, S. Y., Cheow, C. S., \& Dzulkifly, M. H. (1999). Effect of steaming time on the linear expansion of fish crackers ('keropok'). Journal of the Science of Food and Agriculture, 79(11), 1340-1344.
http://dx.doi.org/10.1002/(SICI)1097-0010(199908)79:11<1340::AIDJSFA352>3.0.CO;2-C.

Kyaw, Z. Y., Yu, S. Y., Cheow, C. S., Dzulkifly, M. H., \& Howell, N. K. (2001a). Effect of fish to starch ratio on viscoelastic properties and microstructure of fish cracker ('keropok') dough. International Journal of Food Science \& Technology, 36(7), 741-747. http://dx.doi. org/10.1046/j.1365-2621.2001.00481.x.

Kyaw, Z. Y., Cheow, C. S., Yu, S. Y., \& Dzulkifly, M. H. (2001b). The effect of pressure cooking on the microstructure and expansion of fish cracker ('keropok'). Journal of Food Quality, 24(3), 181-194. http://dx.doi.org/10.1111/j.1745-4557.2001.tb00601.x.

Neiva, C. R. P., Machado, T. M., Tomita, R. Y., Furlan, E. F., Lemos Neto, M. J., \& Bastos, D. H. M. (2011). Fish crackers development from minced fish and starch: an innovative approach to a traditional product. Ciéncia e Tecnologia de Alimentos, 31(4), 973-979. http:// dx.doi.org/10.1590/S0101-20612011000400024.

Nguyen, T.T., Le, T.Q., \& Songsermpong, S. (2013). Shrimp cassava cracker puffed by microwave technique: effect of moisture and oil content on some physical characteristics. KasetsartJ, 47, 434-446.

Nurul, H., Boni, I., \& Noryati, I. (2009). The effect of different ratio of dory fish to tapioca flour on the linear expansion, oil absorption, colour and hardness of fish crackers. International Food Research Journal, 16, 159-165. Retrieved from http://ifrj.upm.edu.my

Okraku-Offei, G. (1974). Trials in the production of fish crackers. Ghana Journal of Agricultural Science. 7, 139-142. Retrieved from http://gains.org.gh/articles/gjas_v7_2_p139_142.pdf

Özoğul, Y., Özoğul, F., \& Alagoz, S. (2007). Fatty acid profiles and fat contents of commercially important seawater and freshwater fish species of Turkey: a comparative study. Food Chemistry, 103(1), 217-223. http://dx.doi.org/10.1016/j.foodchem.2006.08.009.

Teixeira, M. B. F., Tobinaga, S., \& Misawa, F. T. (2000). Some theoretical and experimental considerations on the thin-layer drying of fish crackers: product expansion assessment. Draying Technology, 18(12), 1-19. http://dx.doi.org/10.1080/07373930008917690.

Wang, Y., Zhang, M., \& Mujumdar, A. S. (2012). Influence of green banana flour substitution for cassava starch on the nutrition, color, texture and sensory quality in two types of snacks. LWT-Food Science and Technology, 47(1), 175-182. http://dx.doi.org/10.1016/j. lwt.2011.12.011. 